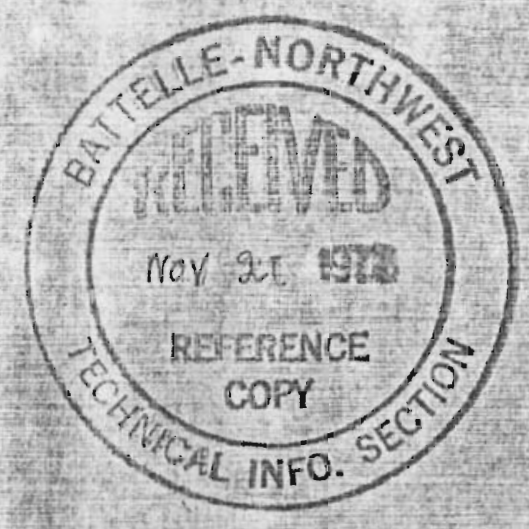

COMP - A BASIC Language Nonlinear Least-Squares

Curve Fitting Program

by

J. M. Thomas

M. I. Cochran

C. R. Watson

L. L. Eberhardt

November 1977

Prepared for the

U.S. Department of Energy

under Contract EY-76-C-06-1830 
33679000517864

PNL-2409

UC-11

\section{COMP - A BASIC Language Nonlinear Least-Squares Curve Fitting Program}

by

1. M. Thomas

M. I. Cochran

C. R. Watson

L. L. Eberhardt

November 1977

Battelle

Pacific Northwest Laboratories

Richland, Washington 99352 


\section{CONTENTS}

\section{INTRODUCTION}

COMPUTER ENV IRONMENT

PROGRAM DESCRIPTION .

REQUIRED INPUT .

BASIC CODING FOR A MODEL SECTION OF COMP . . . . . . . 8

AVAILABLE MODELS

AN EXAMPLE OF COMP RUN ON A PDP $11 / 70$

LOGIN PROCEDURE

LIST PREVIOUSLY CREATED DATA FILE . . . . . . . . . 13

INVOKE BASIC INTERPRETER . . . . . . . . . . $\quad .13$

RUN COMP VERSION WHICH CONTAINS NEEDED MODEL . . . . . . 14

EXIT COMP. . . . . . . . . . . . . 19

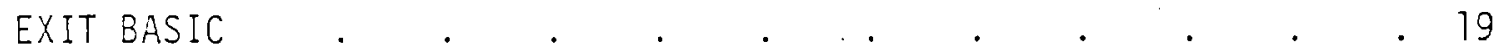

EXIT SYSTEM . . . . . . . . . . . . . . . 19

REFERENCES . . . . . . . . . . . . . . . . . . . . 21

APPENDIX A: USER'S GUIDE FOR COMP ON A DEDICATED PDP 11/34 . . . A.1 APPENDIX B: USER'S GUIDE FOR INTERACTIVE USE OF COMP ON A

REMOTE PDP $11 / 70$. . . . . . . . . B.1

APPENDIX C: PROGRAM LISTINGS . . . . . . . . . . . . . . C.1 
COMP - A BASIC LANGUAGE NONLINEAR LEAST-SQUARES

CURVE FITTING PROGRAM

\section{INTRODUCTION}

Most mathematical models which describe biological processes contain nonlinear terms. While there are many possible nonlinear mathematical models that may describe and adequately fit biological data, usually only one (sometimes two and often none) are useful beyond descriptive purposes because they are derived from a consideration of fundamental biological principles. Parameters in these models are usualiy meaningful because they represent an important aspect of the process. These parameters are usually estimated using nonlinear least-squares techniques on large computers. Fitting mathematical expressions, thought to describe experimental data, is sometimes considered an art because the final parameter estimates obtained from the computer algorithm are a function of the accuracy of initial "guesstimates" for these values. Thus, computer algorithms can either fail completely, give erroneous estimates, or converge to best (true?) solutions.

The following steps typically lead to fitting a mathematical function to biological data: 1) the data are organized and cursorily examined; 2) a plot is devised (sometimes several are tried on different types of graph paper); 3) a hypothesis is generated which may express the process as a model (i.e., are the changes linear, exponential, or logistic?); 4) one model is chosen to represent the process; 5) parameters in the model which allow the best fit of the function (nonlinear least-squares estimates) to the data are calculated, usually by complicated codes on large computers. Often several runs are necessary, using different initial "guesstimates" of parameters in order to obtain a best fit (and sometimes failure); and, 6) the mathematical model and data are plotted. Sometimes residual (observed minus predicted) plots are made to evaluate the adequacy of the model. 
We have developed an interactive BASIC code which runs on both a PDP $11 / 70$ or PDP $11 / 34$ computer to help perform the steps outlined above and to reduce the lengthy turnaround time associated with many runs on batch systems. The key to the system is the reenterant nature of the curve fitting routine (allowed only. with an interpreted language such as BASIC). In general, the user supplies estimates of the parameters for a selected model (18 are currently available). The program calculates a requested number of iterative refinements (hopefully improvements) to the parameter estimates in an attempt to minimize the squared deviations between the values predicted by the model and the observed data. During program execution the user can observe whether the results are logical. If not, the process may be stopped, new parameter estimates tried, the current fit examined, the process of iteration started again, or a new model selected. Detailed users guides for running COMP on the POP $11 / 34$ and $11 / 70$ are in Appendices $A$ and $B$, respectively. 


\section{COMPUTER ENV IRONMENT}

COMP was written in CSTS BASIC for a UNIVAC 1108 and subsequently converted to BASIC-11 on two different minicomputers. Operating parameters relative to these three machines are summarized below:

\begin{tabular}{|c|c|c|c|}
\hline NAME & UNIVAC 1108 & PDP $11 / 70$ & PDP $1.1 / 34$ \\
\hline OPERATING SYSTEM & INFONET & IAS & $\mathrm{RT}-11$ \\
\hline LANGUAGE & CSTS BASIC & BASIC -1$\}^{(a)}$ & BASIC-11(a) \\
\hline $\begin{array}{l}\text { CORE AVAILABLE TO } \\
\text { BASIC USER }\end{array}$ & $32 K$ & $8 K$ & $16 K$ \\
\hline NUMBER OF I/O DEVICES & MANY & SEVERAL & ONE VT 52 \\
\hline STORAGE AVAILABLE & $\begin{array}{l}\text { UNLIMITED } \\
\text { DRUMIS, DISK } \\
\& \text { TAPE }\end{array}$ & $\begin{array}{l}\text { MODERATE } \\
\text { ONE 8\&M BYTE } \\
\text { DISK, ONE TAPE } \\
\text { DRIVE }\end{array}$ & $\begin{array}{l}\text { LIMITED } \\
\text { TO CAPACITY } \\
\text { OF DISKETTE }\end{array}$ \\
\hline
\end{tabular}

Access to INFONET from this location was terminated in June 1977, so we have focused this document on the two PDP versions of COMP.

To reduce the size of COMP to fit available core in the $11 / 34$, extensive use of OVERLAY was necessary. OVERLAY allows the main part of the program to reside in core, while certain segments such as the selected model, are added to the program from a diskette as needed.

This feature is not available in IAS-BASIC-11 on the 11/70. Therefore, COMP was divided into five separate programs, each containing up to five models. The User decides which program to request from the disk to run a selected individual model.

(a) Although these have the same name they are not identical. 


\section{PROGRAM DESCRIPTION}

COMP is an interactive nonlinear least squares routine written in BASIC language and used to obtain estimates of parameters in nonlinear functions and to approximate their associated statistical errors. The program uses the linearizing (or Taylor Series) expansion of partial derivatives outlined in Draper and Smith, (1966, pp. 267-270). Therefore, partial derivatives must be supplied (as well as the function) by the user for any new models not currentiy contained in the programs. It should be noted that when a linearizing method is used to estimate parameters in a nonlinear model, all the usual procedures of linear regression theory can be applied. However, the results so obtained are only valid insofar as the linearized form approximates the true model. All of the statistics computed by COMP should be viewed with this restriction in mind.

The output of COMP inciudes the variance-covariance matrix, t-tests for parameters, Von Neumann's ratio [Bennett and Franklin (1954, pp. 678-679)], observed, predicted and residual values, the error mean square, and an optional procedure to evaluate heteroscedasticity. In the latter procedure the absolute values of the residuals are fit using a linear regression model. Thus, deviations which are significantly larger as $X$ increases (usually $X$ is time) may be detected using the linear regression. One explanation for such behavior may be multiplicative rather than additive errors. 


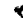




\section{REQUIRED INPUT}

A summary of the dialogue is shown below (a return is implicit after each User entry):

COMPUTER GENERATED QUESTION

LISTING OF MODELS?

MODEL NUMBER

ENTER $\#$ OF DATA POINTS

ENTER $*$ OF PARAMETERS

INPUT FILE?

OUTPUT FILE ALSO?

SAVE ORIGINAL DATA

OR RESIDUALS
PROGRAM VARIABLE USER SUPPLIED NAME ANSWERS
A1

K

$1=$ First model

2 = Second model and so on, until

$1.8=$ Eighteenth mode 1

$N=$ Number of $(X, Y)$ pairs.

1 = Number of parameters for the model: $M>6$ requires program modifications.

D1

27

28

$0=$ No.

1 = Yes. Print a list of available models and their respective code numbers.

$\begin{aligned} N \quad N= & \text { Number of }(X, Y) \text { pairs. } \\ M \quad 1= & \text { Number of parameters for the } \\ & \text { model: } M>6 \text { requires program } \\ & \text { modifications. }\end{aligned}$

$0=$ No. Input will come from keyboard.

1 = Yes. Data are on a file.

$0=$ No

$1=$ Yes

1 = Yes. Save a file of the original $X, Y$ pairs.

2 = Save a file of the residuals and corresponding $X$ values.

When using input or output files, their names will be requested, i.e.:

INPUT FILE NAME?

-.... DAT

OUTPUT FILE NAME?

- - - . OUT

If an input file is not used the following questions will be asked:

LIST OBSERVATIONS ON Y

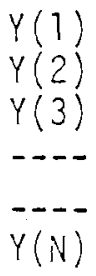


LIST SAMPLING TIMES

(Corresponding to $x$ )

$T(1)$

$T(2)$

$T(3)$

$-1-$

$T(N)$

After data input (either via files or keyboard) the following questions will be asked:

ENTER PARAMETER GUESSES

$$
\begin{aligned}
& P(1) \\
& P(2) \\
& P(3) \\
& \\
& P(M)
\end{aligned}
$$

ENTER $\#$ OF ITERATIONS

N2

Zero will result in a check on "guesstimates" if entered at the first iteration (i.e., observed and predicted values are printed). After one or more iterations, the program will give summary statistics as well, if zero is entered.

BASIC CODING FOR A MODEL SECTION OF COMP

To add a model to COMP, the User must write BASIC statements for the model, the partial derivative(s), residuals and convergence criteria. We illustrate this with the Gompertz Growth Model which is found on page 8 in Appendix $\mathrm{C}$.

For the Gompertz Growth Model:

$$
y_{i}=a e^{-b e^{-c X_{i}}}
$$

The BASIC representation is:

$$
F(I, I)=P(1) \star E X P(-P(2) \star E X P(-P(3) * T(I)))
$$




$$
\text { Where } \begin{aligned}
F(I, 1)=Y \\
P(1)=a \\
P(2)=b \\
P(3)=c \\
T(I)=X \text { or in this case - time. }
\end{aligned}
$$

The partial derivatives of the parameters with respect to $Y$ are:

$$
\begin{aligned}
& \text { 1) }=\frac{\partial a}{\partial Y_{i}}=e^{-b e^{-c X_{i}}} \\
& \text { 2) }=\frac{\partial 0}{\partial Y_{i}}=-a e^{-b e^{-c X_{i}} \star e^{-c X_{i}}} \\
& \text { 3) }=\frac{\partial c}{\partial Y_{i}}=a e^{-b e^{-c X_{i}} \star b X_{i} \star e^{-c X_{j}} .}
\end{aligned}
$$

The BASIC representations are:
1) $X(1, I)=\operatorname{EXP}(-P(2) \star \operatorname{EXP}(-P(3) \star T(I)))$
2) $X(2, I)=-F(I, 1) \star E X P(-P(3) \star T(I))$
3) $X(3, I)=F(I, 1) * P(2) * T(I) * \operatorname{EXP}(-P(3) * T(I))$

For the residuals:

$$
R_{i}=Y_{i} \text { (OBS) }-Y_{i} \text { (PREDICTED) }
$$

The BASIC statement always is:

$$
R(I, I)=Y(I, I)-F(I, I)
$$

To compute the convergence criterion:

$$
c=\sum_{i=1}^{n} R_{i}\left(\partial a / \partial Y_{i}+\partial b / \partial Y_{i}+\partial c / \partial Y_{i}\right)
$$


The BASIC statement is:

$$
C=C+R(I, 1) *(X(1, I)+X(2, I)+X(3, I))
$$

For another mociel, the appropriate partials would be included in the area bracketed.

All of the above BASIC statements are included in a FOR 100p ( $I=1$ to $\mathrm{N}$ ) terminated by NEXT I and RETURN. 


\section{AVAILABLE MODELS}

Page

Description

One Compartment

Exponential

Two Compartment

Exponential

Three Compartment

Exponential

Exponential

Turnover

Exponential Uptake

(Starts at $y=0$, $t=0$ )

Power Function

Gompertz Growth

Curve

Laird Reformulation

of Gompertz Growth

Curve

Logistic Growth

Curve

Mitscherlich

Gamma Uotake

Gamma Decay

Log Gamma Uptake

Log.Gamma Decay

Log Exponential

Uptake (Mode?

Number 5)
Equation

$Y=a e^{-b t}$

6

$y=a_{1} e^{-b_{1} t}+a_{2} e^{-b_{2} t}$

$y=a_{1} e^{-b_{1} t}+a_{2} e^{-b_{2} t}+a_{3} e^{-b_{3} t}$

$y=a t e^{-b t}$

8

$Y=a\left(1-e^{-b t}\right)$

7

$Y=a t^{b}$

$Y=a e^{-b e^{-c t}}$

$y=a e^{\left[b / c\left(1-e^{-c t}\right)\right]}$

$y=\frac{a}{1+e^{(b-c t)}}$

$y=a+b e^{-c t}$

$Y=a\left[1-(1+t / b)^{-c+1}\right]$

9

$Y=a[1+(t / b)]^{-c}$

9

$\log Y=\log a+\log \left[1-(1+t / b)^{-c+1}\right] \quad 10$

$\log Y=\log a-c[\log (1+t / b)]$

10

$\log Y=\log a+\log \left(1-e^{-b t}\right)$ 
One Compartment

with Exponential

Input

$$
\begin{aligned}
& Y=\frac{a}{(b-c)}\left[e^{-c t}-e^{-b t}\right] \\
& Y=a+b t+c t^{2} \\
& Y=a+b t
\end{aligned}
$$

Linear 


\section{LOGIN PROCEDURE}

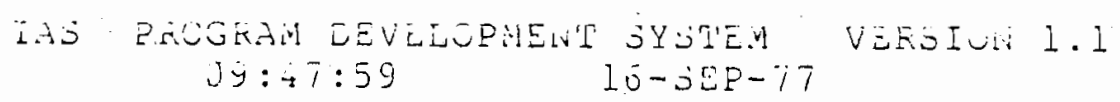



5iscomus?

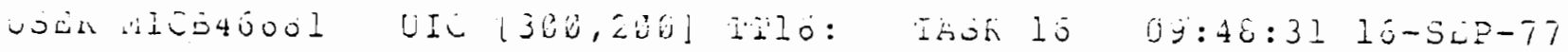

\section{LIST PREVIOUSLY CREATED DATA FILE}

EDS) TYZE LIETHC.OAT

$1,51.3$

$5,5 \div .0$

$1,4,7$

$15,-2.5$

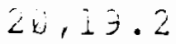

$30,10.2$

$4,0.3$

落,

$30,3.25$

$70,2.50$

INVOKE BASIC INTERPRETER

ELOD EASOL

IAj BASIC VII

FEALY 
RUN COMP VERSION WHICH CONTAINS NEEDED MODEL

RUL CUNE2.EAS

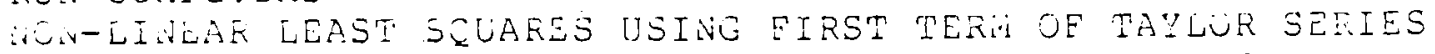

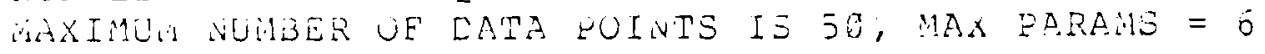

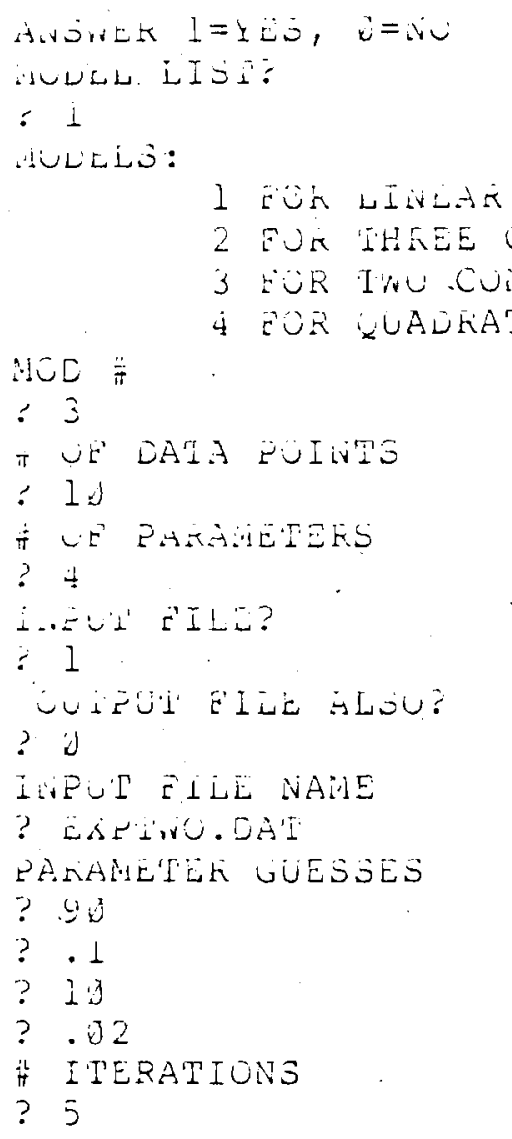

Select two compartment exponential model. There are 10 data pairs; see file 1 isting above.

The model contains four parameters to estimate. Data are from an input file; see above.

No output file will be created.

Name of previously created data file.

Users initial guesses at the four unknown parameters in:

$$
y=a e^{-b t}+c e^{-d t}
$$

Allow five "passes," through the algorithm. seeking better (improved) estimates of the parameters.

PARAMERER VALUES, CONVERGENCE CRITERION

(5) Successive Estimates of

\begin{tabular}{|c|c|c|c|c|}
\hline$a=P(1)$ & $b=P(2)$ & $c=P(3)$ & $d=P(4)$ & $\begin{array}{l}\text { the convergence } \\
\text { criterion }\end{array}$ \\
\hline 89.4524 & .100471 & 11.0953 & .0217557 & -721.405 \\
\hline 89.3733 & .100538 & 11.1773 & .9217587 & -64.6721 \\
\hline 89.3722 & .208539 & 11.1784 & .0217902 & -.01577 \\
\hline 89.3722 & $.10 ن 539$ & 11.1704 & .3217932 & $-7.00199 \mathrm{E}-83$ \\
\hline 89.3722 & .185539 & 11.1704 & .0217902 & $-4.76368 E-133$ \\
\hline
\end{tabular}


The fitting process is proceeding wel1 because:

a) The parameter estimates stabilized (to 6 significant digits) at iteration 3.

b) The convergence criterion is steadily approaching zero. Usually a steady decline toward zero, but oscillating between plus and minus values is desirable.

The following four additional (but probably not needed) iterations illustrate this behavior for the convergence criterion:

ITERALIUNS

? 2

\begin{tabular}{|c|c|c|c|c|}
\hline$\dot{4} \cdot 3722$ & .122539 & 11.1784 & .0217502 & $1.3 \div 7542-103$ \\
\hline 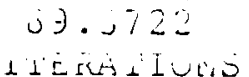 & .100539 & 11.1754 & $.0217 y 22$ & $-3.17574 E-3$ \\
\hline vits & & & & \\
\hline $\begin{array}{l}09 \cdot 312 j \\
ن \dot{y} \cdot 123\end{array}$ &  & $\begin{array}{l}11.1704 \\
11.1733\end{array}$ & $\begin{array}{l}.0217502 \\
.0217902\end{array}$ & $\begin{array}{r}-4.575 i u L-j 4 \\
5.55057-63\end{array}$ \\
\hline
\end{tabular}

Since satisfactory convergence has been obtained enter zero to obtain the final results.

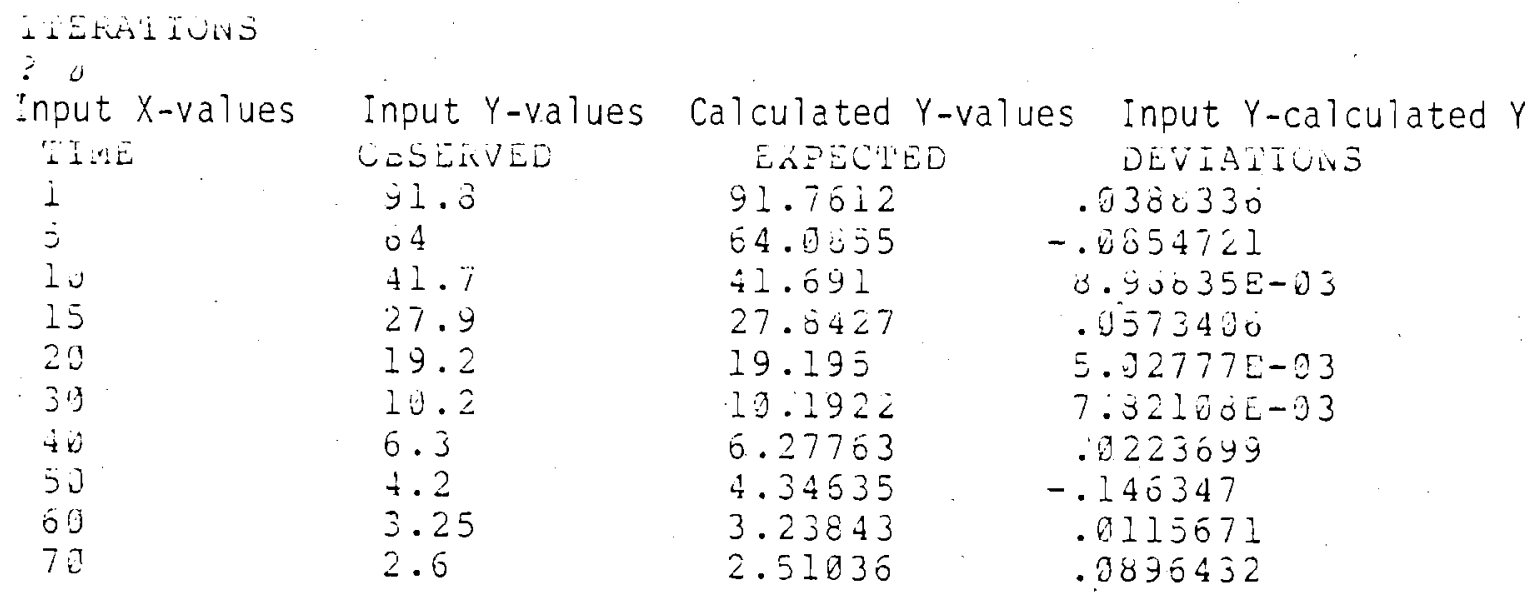


The estimated variance - covariance matrix is arranged as follows:

$$
\begin{array}{lllll}
P(1) & \frac{p(1)}{s^{2} p(1)} & \frac{p(2)}{s^{2} p(1) p(2)} & \frac{p(3)}{s^{2} p(1) p(3)} & \frac{P(4)}{s^{2} p(1) p(4)} \\
P(2) & & s^{2} p(2) & s^{2} p(2) p(3) & s^{2} p(2) p(4) \\
P(3) & & & s^{2} p(3) & s^{2} p(3) p(4) \\
P(4) & & & & s^{2} p(4)
\end{array}
$$

and the blanks below the diagonal values would simply be repeats of the above diagonal values. The square root of the diagonal parameter variances (i.e., the standard deviations) are used to calculate the t-tests for the parameters which are printed below (i.e., parameter estimate/standard deviation $=t$ ). Paraneter covariances can be interpreted "somewhat" like a simple correlation coefficient. The sign indicates the direction of joint relationship and the size indicates the strength of the joint relationship among the two parameters. Small covariances allow "easier" fits. In this example parameters a and $C[P(1)$ and $P(3)]$ are jointly related. Since they enter linearly the association did not cause extreme difficulty.

$\begin{array}{lrlr}\text { VARIANCE-COVAEIALCE MATRIA } & & \\ .461678 & -5.01326 E-04 & -.483221 & -7.77393 E-04 \\ -5.01326 E-04 & 6.43914 E-07 & 5.51226 E-04 & 8.50792 E-07 \\ -.403221 & 5.51226 E-04 & .516341 & 8.25350 E-04 \\ -7.77393 E-04 & 0.50702 E-07 & 8.25350 E-04 & 1.37291 E-06\end{array}$

The Von Neumann ratio is a statistic used to detect runs and is computed using squared successive differences in residuals (labeled deviations above) and the variance about regression. To determine statistical significance of the calculated ratio compare it to the critical values in Table 1 . The expected value for a random series of runs is two, but as can be seen from Table 1 a statistically significant value depends on sample size. In this example $(n=10)$ a calculated statistic less than 1.06 or greater than 2.94 would be statistically significant $(P<0.05)$. A statistically high ratio indicates short-term oscillations and significantly small values indicate longer-term trends or nearly stable conditions (i.e. nonrandomness). For ratios based on more than 25 observations the t-statistic is computed. High positive t-values indicate long-term trends, high negative values indicate 
TABLE 1. Critical Values for the Von Neumann Ratio(a)

\begin{tabular}{|c|c|c|c|c|}
\hline \multirow{2}{*}{$\begin{array}{c}\text { Sanple } \\
\text { Size }\end{array}$} & \multicolumn{2}{|c|}{$\begin{array}{c}\text { Upper Critical } \\
\text { Values }\end{array}$} & \multicolumn{2}{|c|}{$\begin{array}{c}\text { Lower Critical } \\
\text { Values }\end{array}$} \\
\hline & $a=0.01$ & $a=0.05$ & $\therefore=0.01$ & $a=0.05$ \\
\hline 4 & 0.63 & 0.78 & 3.37 & 3.22 \\
\hline 5 & 0.54 & 0.32 & 3.46 & 3.18 \\
\hline 6 & 0.56 & 0.89 & 3.44 & 3.11 \\
\hline 7 & 0.61 & 0.94 & 3.39 & 3.06 \\
\hline 8 & 0.66 & 0.98 & 3.34 & 3.02 \\
\hline 9 & 0.71 & 1.02 & 3.29 & 2.98 \\
\hline 10 & 0.75 & 1.06 & 3.25 & 2.94 \\
\hline 11 & 0.79 & 1.10 & 3.21 & 2.90 \\
\hline 12 & 0.83 & 1.13 & 3.17 & 2.87 \\
\hline 15 & 0.92 & 1.21 & 3.08 & 2.99 \\
\hline 20 & 1.04 & 1.30 & 2.96 & 2.70 \\
\hline 25 & 1.13 & 1.37 & 2.87 & 2.63 \\
\hline
\end{tabular}

(a) Adapted from Bennett and Franklin, p. 679, 1954.

short, rapid oscillations. For practical purposes, a value for $t$ of \pm 2 can be considered statistically significant $(P<0.05)$. In the example, the ratio (1.40) indicates no significant departure from expected "residual runs."

The calculated variance about the regression is the traditional error mean square.

\begin{tabular}{|c|c|c|}
\hline UN WEUMANN & KATIO & CALCULATEU VARIAN \\
\hline CALCULATED & $N>25=T$ & $\begin{array}{l}\text { ABOUT RECRESOIOI } \\
7.05932 E-D 3\end{array}$ \\
\hline
\end{tabular}






\section{EXIT COMP}

TEST RESIDUALS?

$? 0$

$\overline{R E A D Y}$

\section{EXIT BASIC}

$3 Y 2$

1E:jo:51 TASK TERMIÃA'ION

COKE JIEL 18K CPU TIME $13.1 \mathrm{~J}$

\section{EXIT SYSTEM}






\section{REFERENCES}

Bennett, C. and N. A. Franklin. 1954. Statistical Analysis in Chemistry and the Chemical Indusiry. John wiley \& Sons, N.Y.

Oraper, N. R. and H. Smith. 1967. Applied Regression Analysis. John Wiley \& Sons, N.Y. 


\section{APPENDIX A}

USER'S GUIDE FOR COMP ON A DEDICATED POP $11 / 34$

, 


\section{APPENDIX A. USER'S GUIDE FOR COMP ON A DEDICATED POP $11 / 34$}

A diskette labeled 'COMP' contains all the BASIC programs necessary for using the overlayed version of COMP. A second diskette (labeled 'SYSTEMS') contains the computer operating system (RT-11). Assuming the 'System' diskette is loaded in the left slot (labeled DK-O) and the 'COMP' is loaded in the right slot (labeled $O K-1)$ the following procedure should be followed:

I. DEAD START If the computer is on, skip to step II. Turn computer power switch to ON (located on computer). Turn the CRT. (Descope) power ON (switch on right side of CRT). Depress the BOOT-INIT switch (on computer). The CRT should respond by displaying four meaningless six-digit numbers and a dollar sign. Depress the Caplock key (on CRT) and enter DX on the CRT followed by $(R)$. (a) The CRT will display: RT-11SJ VO2C-02. Enter today's date, i.e., DATE 19-OCT-77 (R) ${ }^{(a)}$ (do not fail to enter the word DATE).

II. RUNNING BASIC

\section{Enter: $R$ BASIC $(R)$}

CRT wi1l display: BASIC VO1B-02

Enter another $(R)$.

CRT will display: READY

III. STARTING COMP (If a data file must be created skip to Section $V$.)

Enter: OLD 'DX1:COMP'

CRT will display: READY

Enter: RUN

IV. RUNNING COMP

COMP is interactive, and generally self-explanatory (see preceeding sections for more details). Remember that overlays are used to save computer core, so if a model is chosen, then later a different model is wanted, return to Step III. Failure to do this will result in

(a)Carriage return 
subjecting the data to two models simultaneously and unexpected results will be obtained. The following hints may be useful:

a) If data are to be read from a file, the file must have been previously created (see Section $V$ ). COMP will request the data file name, and it should be supplied without quote marks (i.e., JOHN.DAT).

b) Getting back to READY - to interrupt the program enter two consecutive Control-C's. The screen will display a period. Enter: RE This latter step returns the BASIC mode with program intact. Note: Control-S stops and Control-Q resumes output.

c) Iterations - an answer greater than 0 (zero) will cause the program to try that many iterations. An answer of 0 (zero) will either display a check on your guesstimates or go on to the next step depending on how far the analysis has progressed. An answer of less than zero (a minus number) causes the program to branch back to line 500 which will print the question:

ENTER PARAMETER GUESSES

?

(Note: Line 500 may be referenced when re-entering the program from READY, i.e., GO TO 500)

Parameter guesses can be re-entered and the program run again.

V. CREATING A DATA FILE

On our configuration the only way to create data files is through the CRT keyboard. Those not familiar with PIP or RT-EDIT may use the BASIC program 'DXI:COMPIN' - which will interactively lead one through the file building process.

VI. ADDING NEW MODELS

1. New models are easy to add to CoMP. Assume a four compartment exponential model, model 20, is to be added to COMP. Return to BASIC (see Section IVb above) and enter:

NEW 'DX1:COMP20' 
Now enter model 20 with the following conventions:

a) Line 305 must be of the form:

305 PRINT 'FOUR COMPARTMENT EXPONENTIAL MODEL'

b) Line 320 must contain the number of parameters to be estimated:

$320 M=8$

c). The model must be inserted between lines 2000-4000 but the ine number incrementation is optional.

d) No RETURN or END statement should be used.

e) When finished enter:

SAVE 'OX]: COMP20'.

2. The Main Program - COMP - will need three changes to accept the new model. Change lines:

240 - to 1 ist the new model when a model list is requested

266 - to increase the maximum number of models (K)

285 - to overlay the new model when it is requested

a) To make these changes return to BASIC (Section IVb above) and enter:

OLD 'DXI:COMP'

b) Type in the new lines 240, 266, and 285 .

C) Enter:

REPLACE 'OX1:COMP'

d) Test the changes (make sure there are no errors) by entering: RUN

e) WARNING: If the new model does not run properly and you make changes while in COMP, DO NOT fix it and use the REPLACE command!!! If you do, comp will contain the model which you called via OVERLAY. Make a note of successful changes, then enter the OLD command and use the REPLACE command as out 7 ined in the previous steps. 
APPENDIX B

USER'S GUIDE FOR INTERACTIVE USE OF COMP ON A REMOTE PDP $11 / 70$ 
APPENDIX B. USER'S GUIDE FOR INTERACTIVE USE OF COMP ON A REMOTE PDP $11 / 70$

I. DEAD START (Using a DTC-300 equipped with Microfile)

On the DTC-300 Teletypewriter: Depress the POWER and LINE buttons. Depress the CAP button on the lower right hand side of the keyboard so that all alphabetic characters received and sent are in capital

On the Microfile: letters.

Depress both the POWER and middle top white (labeled HOST) buttons.

On the Coupler: Make sure POWER is on (red button on) and duplex is set to FULL.

Dial the Computer number: 942-7601. When whistiing signal is heard, insert handset in coupler, and check that green light is on. When a PDS is received on the teletypewriter, enter:

LOGIN USER ID PASSWORD(a)

If extraneous material is unwanted, login as shown below:

\section{LOGIN/NO USER ID PASSWORD}

The /NO indicates that no user messages are desired. (b)

List files:

For a listing of ail the BASIC files, or programs, enter [after the PDS]:

$$
\text { DIRECTORY *.BAS; * }
$$

or DIR *.BAS; *

To list all data files, enter:

$$
\text { DIRECTORY *.DAT; * }
$$

or DIR*.DAT;*

(a) An example USER ID is MICB46681 and an example PASSWORD is GEORGE.

(b) See example on page 13. 
II. RUNNING BASIC:

To invoke the BASIC interpreter enter:

BA [after a PDS]

The computer will return:

IAS BASIC VOI

READY

Enter:

RUN and the name of the program

selected for execution (i.e.,

RUN COMP1).

III. STARTING COMP

Use the procedure in Section II to run BASIC. The appropriate program to request will depend on the model chosen, (see Table B-l and also the Chapter on available models for the mathematical representation of each model).

IV. RUNNING COMP

The program is self-explanatory but some detail of its operation is included in Chapters 2 and 3 . Some further operational details peculiar to rurning COMP on the PDP $11 / 70$ are given below.

a) Data files are created by entering EDIT after a PDS. In the

following example, words underlined are User replies while the

other material is printed from the computer.

ENTER EDIT PDS> EDIT

NAME FILE FILE? EXPONE.DAT

[EDI -- CREATING NEW FILE]

INPUT

ENTER DATA $\quad \underline{9.0,2}(R)$

$8.0,2(R)$

$6.2,5(R)(R)$ [Two carriage returns terminate data entry.]

TOP OF FILE $\quad$ TOF

[PAGE 1] 
TABLE B.1. Models in Various COMP Versions Used on PDP $11 / 70$

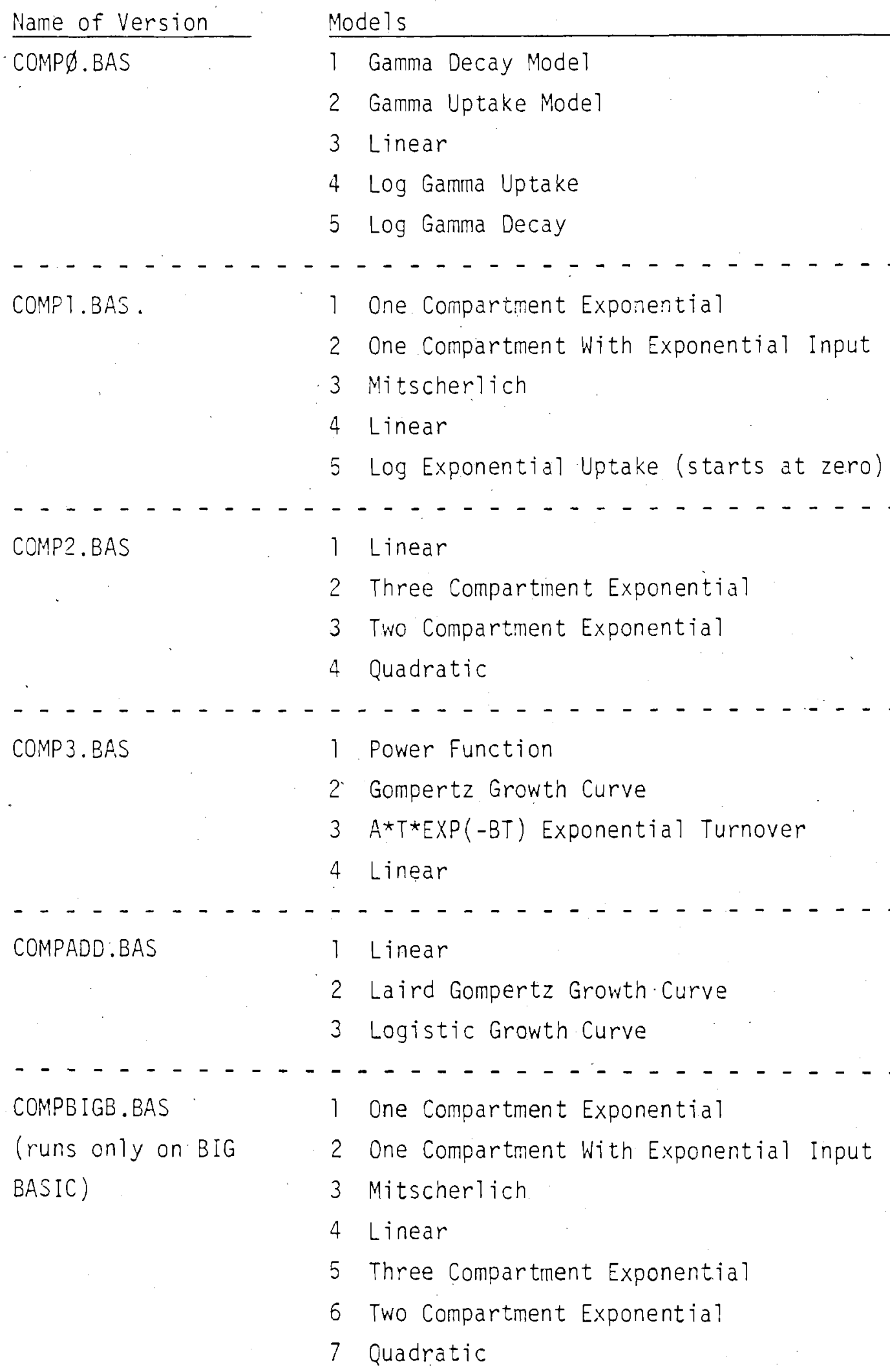






ADDING NEW MODELS TO COMP ON THE PDP $11 / 70$

In order to add new models to the program COMP.BAS a new copy of the existing program called COMPADD.BAS should be made. This version was specificaily constructed to facilitate adding new models. A new copy of COMPADD.BAS is created by issuing the command COPY:

\section{PDS> COPY \\ FROM? COMPADD.BAS \\ TO? COMPLOGI.BAS}

Note: The name COMPLOGI.BAS is an example name, any logical name can be used. the .BAS portion of the command tells the computer that this file is a BASIC file.

As previously stated, underlined characters are typed by the User. This sequence of commands produces a new version of the program COMPADD called COMPLOGI. Additional models can be added to COMPLOGI without changing the orginal program. This is a safety step used in case something goes wrong in changing the new version. If errors are made, delete the new program and start over with the COPY command. 
In order to change the file and add new models, put the file into EDIT mode. This is done by issuing the command:

PDS> EDIT COMPLOGI.BAS

Lines 244-246 contain:

$$
\begin{aligned}
& 244 \text { PRINT "MODELS:" } \\
& 246 \text { PRINT ": } 1 \text { FOR LINEAR" }
\end{aligned}
$$

and can be printed by typing the FIND command:

$$
\text { * FIND } 244
$$

When the contents of line 244 are typed, give an $(R)$ to inform the computer to print the next line also. In this case just after line 248 is the place to. insert the model name being added to the program. This is done by the INSERT command:

The I is a sufficient part of the command. After printing the I the CRT or TTY will drop down one line leaving no characters, just a blank line. The line to be inserted is then typed:

$$
250 \text { PRINT "4 FOR USER SELECTED NEW MODEL" }
$$

When through adding lines, issue two $(R)$ s to return to asterisk, then the next command can be keyed in.

Check a current listing to see where the calculations should be added. In this case, the new model calculations are added at line 6040. REMARK (REM) statements should be inserted just ahead of the lines of calculations. In the COMP version COMPADD, 1 ine 8000 was used for the END statement so the INSERT command needs to be implemented just after the line number prior to line 8000 .

After the last line of the calculations have been added, enter an ( $R$ ) which causes an asterisk to print. Enter:

\section{*TOF}

This command causes EDIT to take the program back to Top of File. At line 260 the model. $\frac{4}{\pi}$ is requested using the variable $k$. To implement the new model, add a line number to the statement at line 620. First find 1 ine 620 :

$$
\text { *IND } 620
$$


The computer prints:

620 ON K GOTO $900,910,975$

Use the CHANGE command to add a new 7 ine number:

$* \mathrm{CH} / 9.15 / 915,925 /$

The computer prints:

620 ON K GOTO 900, 910, 915, 925

A correct GOSUB statement for the new model should be placed at line 925. Once again use the FIND command:

*FIND 920

The computer prints:

920 GOTO 940

Input the letter I. after the asterisk:

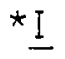

Then type:

$$
\frac{925 \text { GOSUB } 6040}{930 \text { GOTO } 940}
$$

To EXIT the EDIT mode the letters ED are typed in after the asterisk:

*ED

This will save the present version and delete the unchanged program. If you use the EXIT command:

$$
\text { *EX }
$$

both versions will be saved, but only version 2 will have the changes, so the first copy must be manually deleted. When the computer returns:

$$
\text { PDS> }
$$

A successful EXIT from EDIT has been made.

To disconnect the teletype from the computer type LOGOUT. If the BASIC interpreter is being used, enter BYE and the computer will return a POS. 


\section{APPENDIX C}

PROGRAI LISTINGS 


\section{VARIABLES USED IN COMP}

( $n=$ number of pairs of points, $m=$ number of parameters $)$

VARIABLE NAME

\begin{tabular}{|c|}
\hline$A(m, m)$ \\
\hline$B(n, m)$ \\
\hline$D(m, 1)$ \\
\hline$E(m, 1)$ \\
\hline$F(n, 1)$ \\
\hline$H\left(1,2^{\star} m\right)$ \\
\hline$P(m)$ \\
\hline$Q(m)$ \\
\hline$R(n, 1)$ \\
\hline$S(m, m)$ \\
\hline$T(n)$ \\
\hline$V(m, m)$ \\
\hline$x(m, n)$ \\
\hline$Y(n, 1)$ \\
\hline C \\
\hline$K$ \\
\hline$N$ \\
\hline M \\
\hline $\mathrm{N} 7$ \\
\hline N3 \\
\hline$E]$ \\
\hline$T \uparrow$ \\
\hline$V 7$ \\
\hline
\end{tabular}

USE OF VARIABLE

Inverse of $\mathrm{S}(\mathrm{m}, \mathrm{m})$.

Transpose of $x(m, n)$.

Product of $X(m, n) * R(n, 1)$.

Product of $A(m, m) * D(m, 1)$ and change in parameter value(s) for the current iteration.

Expected values for $Y$ based on the selected model.

$H(1,1)=$ New (refined) parameter estimates.

$H(1, m+1)=$ Convergence criterion.

Initial parameter guesstimates and new (calculated) parameter values.

Temporary storage for previous $P(m)$ values.

Residuals, $Y-F$.

Product of $X(m, n) * B(n, m)$.

Observations on $x$ (usually sampling times).

Variance-Covariance matrix.

Partial derivative of each parameter with respect to $Y$, evaluated at each sampling time.

observations on $Y$

Convergence Criterion

Model Selected

Number of Pairs of Points

Number of Parameters

Number of Iterations

Set to 0 (zero) when $1 \mathrm{~V} 2$ is entered as zero.

Result in printing check on guesstimates.

Von Neumann Ratio (Test for residual runs)

Use Tatle 11.5 on page 679 in Bennett and. Frank. in, 1954, for Table 1, page 17, this report.

If $N>25$ this t-test approximation for significant residual runs is printed. Use an ordinary t-table.

Residual Variance 


\section{LISTING OF COMP FOR PDP $11 / 34$}

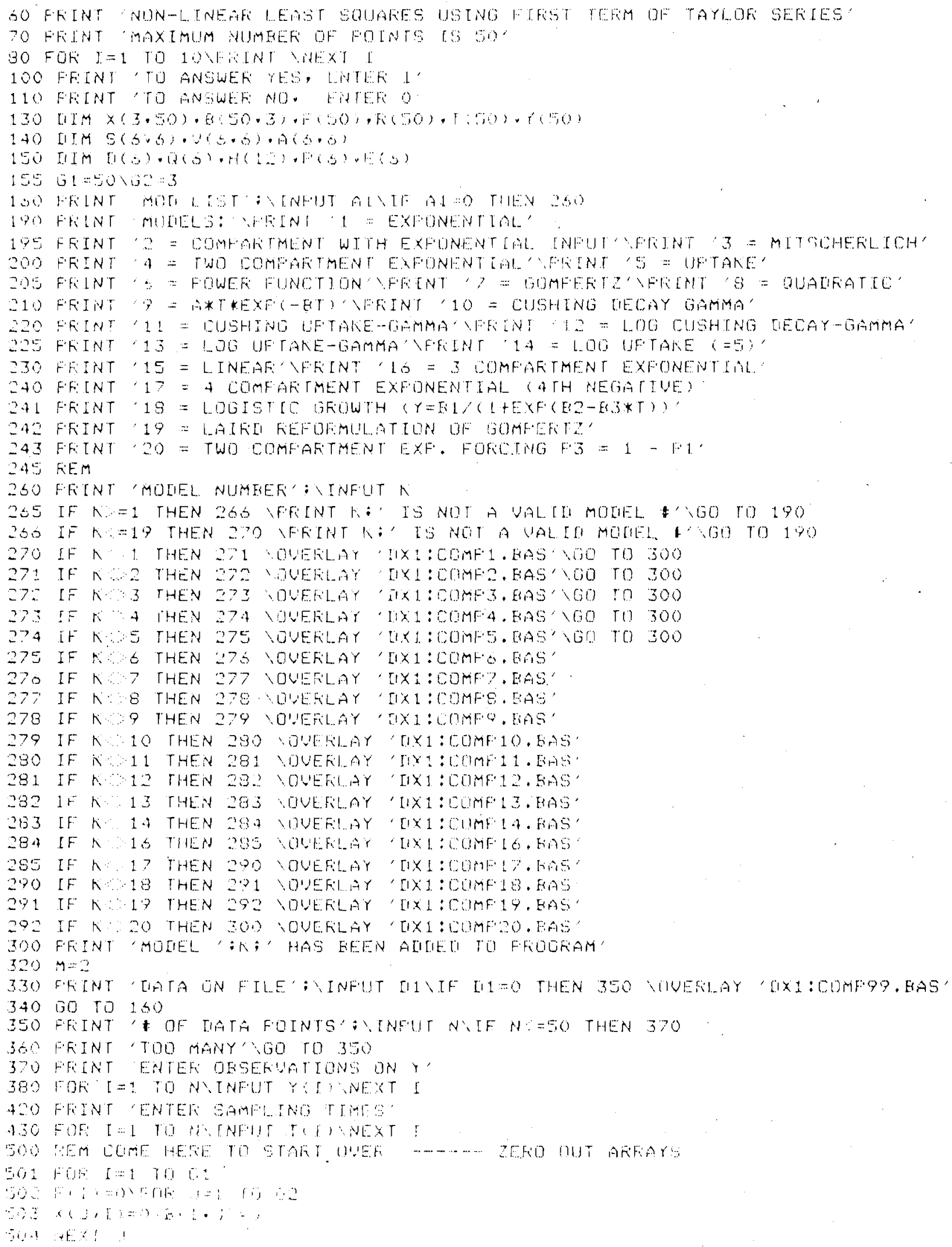




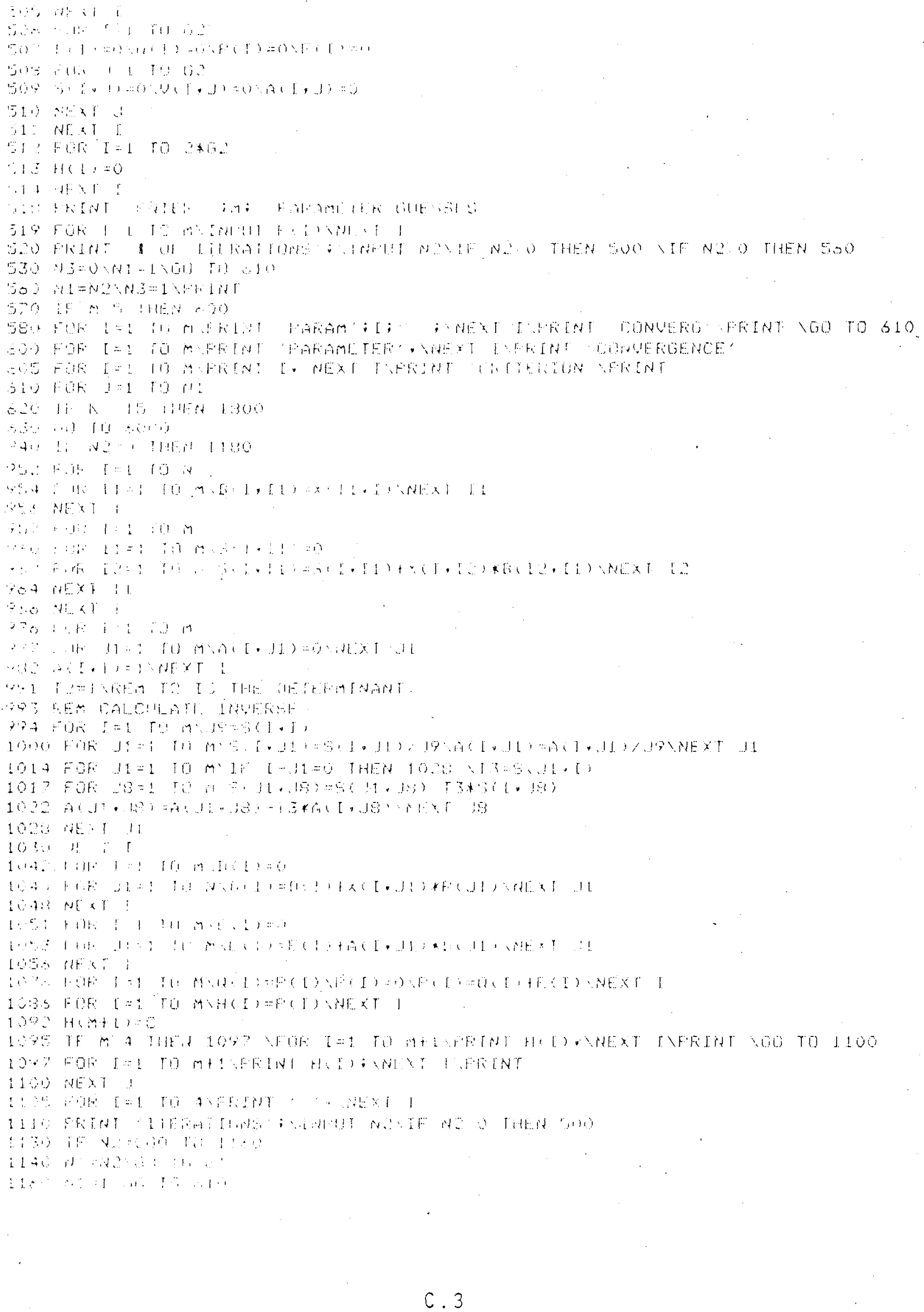









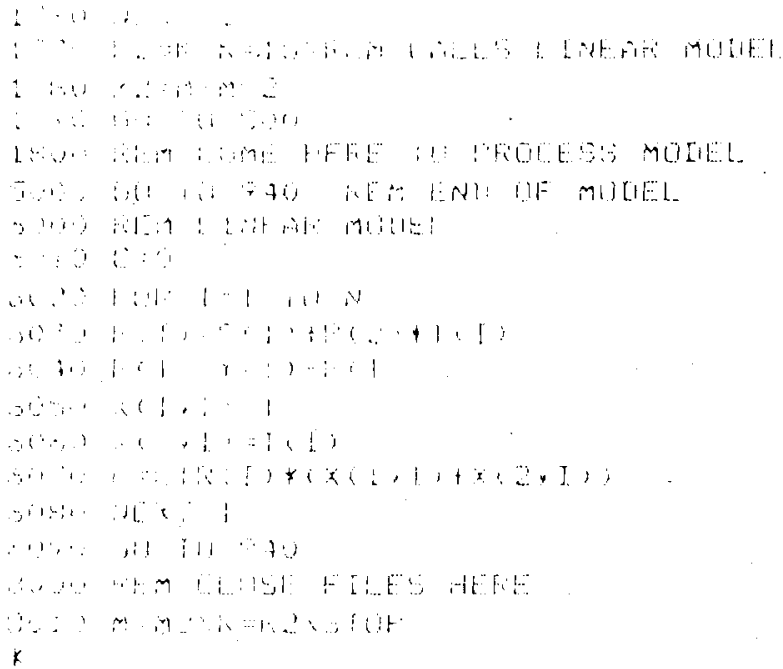




\section{OVERLAID MODELS FOR COMP (PDP 11/34)}

COMP1.BAS

305 FFINT 'EXFONENTLAL MOLEL F = FLWEXF(-FOT)'

$320 \quad+1=2$

1310 WEM SUBFOUTINE FOR EXFONENTIAL MOTEL.

$1820 \quad C=0$

1830 FOF T:=1 TO N

$1.840 F(I)=F(1) \times E \times F(-F(2) * T(I))$

$1850 \quad \because(I)=Y(I)-F(I)$

$1.860 \times(1, I) \cdots E X F(-F(2) \times T(T))$

$1870 \times(2, I)=\cdots F(1) * T(I) * E X F(-F(2) * T(I))$

$18800=0+f(J) *(X(1, I)+X(2, I))$

1890 NEXT T.

COMP2.BAS

305 FIRT 'COMFAKTMENT WITH EXFONENTIAL IHFUT'

$320 \quad M=3$

1920 FEM SUEFOUT LNE FOF COMFAFTMENT WITH EXFOMENT IAL INFUT

$19.30 \quad C:=0$

1946) FEF $[\because 1$ TC $\mathrm{N}$

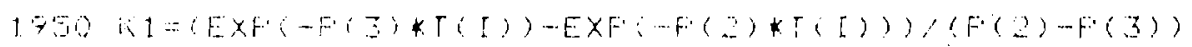

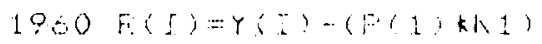

$1970 \div(I)=F \cdot(;)+1.2$

$1890(14,3)-1,1$

$1990 \times(2, I)=(F(1) * \Gamma(I) * E \times F(-F(2) * T(I)))(F(2)-F(3))-F(1) * K 1 /(F(2)-F(3))$

$2000 \times(3, I)=(F+1) * 1) /(F(2)-F(3)-(F(1) * T(I) * E X F(-F(3) * T(I)) /(F(2)-F(3))$

$2010 C=C+F(1) *(x(1,1)+x(2, I)+x(3, I))$

2020 INEXY I

COMP3.BAS

305 FHINT AMTSCHEFI. TCH HOIEL_'

$320 \quad n=3$

2050 FEM SUBFOUTINE FOF MTTSCHEFLICH MOREL

$20,50 \quad C=0$

2070 FOK $\mathrm{I}=1$ TO $\mathrm{N}$

$2030 F(I)=F(1)+F(2) * E X F(-F(3) * T(I))$

$2090 \mathrm{~F}(\mathrm{I})=Y(\mathrm{I})-\cdots(\mathrm{I})$

$2100 \times(1, I)=1$

$2110 \times(\Omega, I)=E \times F(-F(3) * T(I))$

$2120 \times(3, I)=-F(2) * T(I)$ WEXF $\left(-F(3)\right.$ * $\left.T^{2}(I)\right)$

$2130 C=\mathrm{C}+\mathrm{F}(\mathrm{T}) *(X(1, \mathrm{f})+X(2, \mathrm{I})+X(3,5))$

2140 NEXT 1

C. 6 


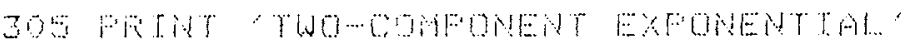

$320 \quad 11=4$

2170 FEM THO COMOWEMT EXHONENTLAL

$2180 \quad 0=0$

$2190 \quad F 05 \quad 1=1 \quad$ rO N

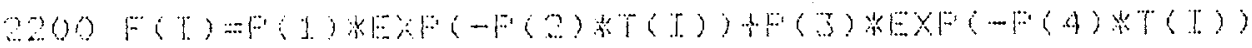

$2010(\mathrm{C})=\mathrm{Y}(\mathrm{I})-F(\mathrm{~S})$



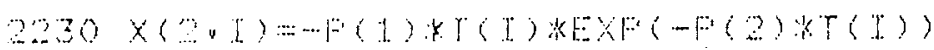

$2230 \times(3, X)=E \times(\ldots F(4) * T(T))$





2300 itEXT I

\section{COMP5.BAS}

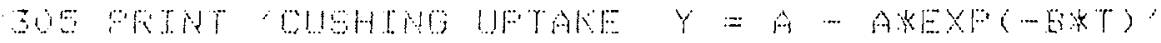

350 in $=2$

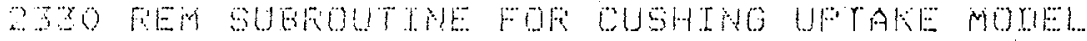

$290 \quad 0=0$

a......

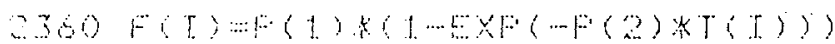

2370 F(I) $\cdots Y(I) \cdots(L)$

$2300 \times(1,1)=1 \cdots E \times(-F(O) \times T(I))$

$239) \times(39 T) \cdots(1) \times T(I) \times E X F(-\cdots F(2) \times T(I))$

$2+000=0+8(1)+(x)+1)+3(2+5)$

$3410 \mathrm{ME} \times \mathrm{T}$ :

\section{COMP5.BAS}

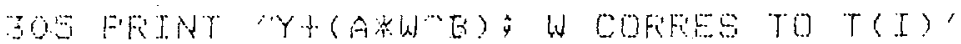

20 in $=2$



$2730 \quad 0=0$

$27 A O$ FOE $\mathrm{I}=1$ TO $\mathrm{N}$

$27 \% F(I)=F(1) *(T(I) \cdots(2))$

$2760 R(I)=Y(I)-F(I)$

$27,0) \times(1+]) \cdots T(I) \cdots F(2)$

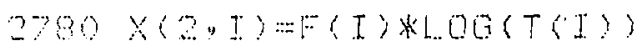

$2>900=0+5(I) *(X(1, I\}+X(2, I) ?$

2900 PEXY I.

C. 7 


\section{COMP7.BAS}



COMP8.3AS

$30 S$ FIRINT 'QUALRATIC MOLEL'

$320 \quad M=3$

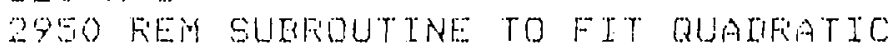

$2960 \quad C=0$

$2070 \mathrm{FOK} I=1 \mathrm{TON}$

$2900 F(I)=F(L)+F(2)$ *T $T(I)+F(3) *(T(I)-2)$

$2990 F(I)=Y(I) F(I)$

$3000 \times(1+1)=1$

$3010 \times(2, \mathrm{I})=\mathrm{T}$ (I. $)$

$3020 \times(3, T)=T(I)=2$

$3030(C=C+F(I) *(X(1, I)+X(2, I)+X(3,[))$

$30-70$ PEXT I

\section{COMPG.BAS}

305 FFINT 'FEFIXTKEXF(-HWT)'

$320 \quad M=2$

3070 RFM SUFFOUTLNE TO FIT ATEXF(-BT)

$3080 \mathrm{C}=0$

$3090 \mathrm{FOF}: \mathrm{I}=1 \mathrm{TO}$ is

$3100 F(T)=F(I)$ WT (I) XEXF'

$3110 F(I)=Y(I)-F(I)$

$3120 \times(1 \cdot T)=T(I) \times E X F(-F(2) * T(I))$

$31,3) \times(2, \mathrm{~T}) \cdots-\mathrm{T}(\mathrm{I}) * \mathrm{~F}(\mathrm{I})$

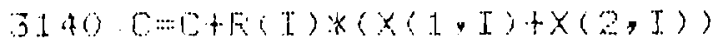

$3150 \mathrm{NEXT} I$ 


\section{COMP10.BAS}

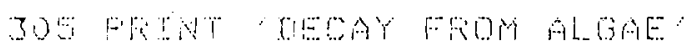

$320 \quad 11 \cdots$

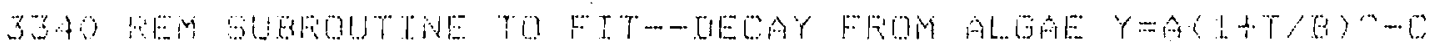

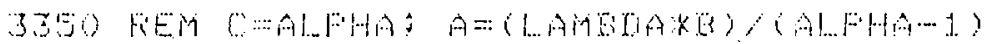

$3350 \quad 0=0$

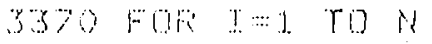

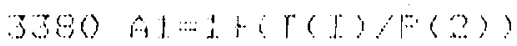

3390 a $2 \cdots$ A. 1 " $(-F(3))$

3400 A $3 \cdots 1$ - $(-\infty)(3 ;-1)$

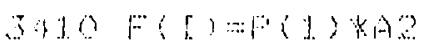

$3+30(\mathrm{~T}) \cdots Y(\mathrm{~T}) \cdots(\mathrm{T})$

$3+30 \times(1,1)=A 2$



$3450 \times(3,1)=-F(1)+A 2 k 1.06(A)$

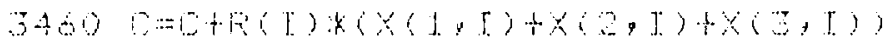

3470 MEखT I.

COMP1 1.BAS



320 ir $=3$



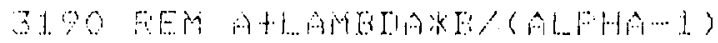

$3200 \quad c=0$



$3220 A 1=1+(T(L) / F(2))$

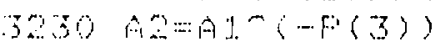

$32+0$ A $3=A J^{\wedge}(-F(3)+1)$

$3250) F(T)=F(1) *(1-93)$

$32,0)(T)=Y(I)-F(T)$

$3270 \times(1+3)=1-43$

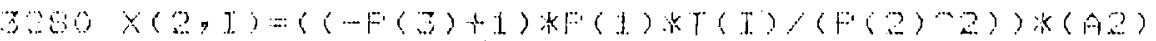

$3290 \times(3, I)=F(1)+A, 2 \times 1 D G(A 1)$

$33000=0+F(I) *(x(1, I)+x(2, I)+x(3, I))$

3310 NEXT I

C.9 


\section{COMP12.BAS}

3OS FWTAT 'LOO FOFM OF LECAY MOREL'

320 iv $\cdots 3$

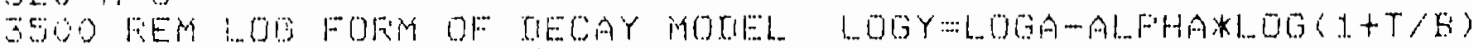



$3500 \quad 0=0$

3530 FOR $I=1$ TO is

$35+0$ A $1=\{1+T(I) / F(2)\rangle$,

3500 A2:F(2) 2

3060 F ( I ) $=1.00(F(1))-F(3) * 1.00(A 1)$

$3570 F(T)=1.06(Y(I)) \cdots(I)$

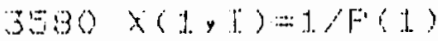

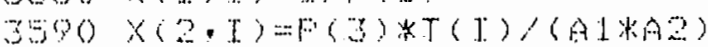

$3600 \times(3 \cdot 1)=-1,00(A .1)$

$3610 \quad C=C+F(T) *(X(1, I)+X(2, I)+X(3, I))$

$3620 \mathrm{NEKT} \mathrm{T}$.

COMP13.BAS

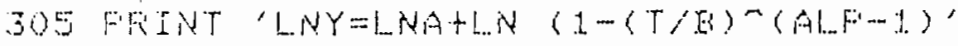

$320 \quad M=3$



$3660 \quad 0=0$

$36 \%$ FOK $I=1$ TO N

$3380 A \pm=1+\{T(T) / F(2)\}$

3.990 किस:

3700 a $=91 \cdots(-\cdots)(3)+1)$

$3710 F(S)=100(F(1))+100(1-(A 3))$

$3720 \mathrm{~F}(\mathrm{I})=\operatorname{LOG}(Y(\mathrm{I}))-F(\mathrm{I})$

$3730 \times(1, I)=1, / F(1)$

$3740 \times(2, I)=(-F(3)+1) * T(I) * A 2 /((1-(A B)) * F(2)-2$

$3750 \times(3, I)=A 3 \times(\ldots 0 G(A L) /(A-(A B))$

$3760 \quad C=C+F([) *(X(1, I)+X(2, I X(3, I))$

3770 REXT I.

\section{COMP14.BAS}

305 FFINT 'LOG FOFM OF UFTAKE MOREL'

320 iो $=2$

3320 FIEM LOQ. FOFH OF UFTAKE MOEEL

$38.40 \quad[=0$

3350 FOIR $\mathrm{J}=1$ TO $\mathrm{N}$

$3970 F(I)=F(1)+100(1-E X F(-F(2) * T(I)))$

$3880 F(I)=Y(I)-F(I)$

$3390 \quad x(1, I)=1$

$3900 \times(2, I)=(T(I) * E \times F(-F(2) * T(I)))(1-E X *(-F(2) * T(I)))$

$3930 \quad C=C+F(T) *(X(1, I)+X(2, I))$

3940 NEXT ! 


\section{COMP15. BAS}

Mode? 15 is LIVEAR in main program COMP (see 1 ines 6000-6090

page $(.5)$

COMP16.BAS



$320,4=0$

$2000(-0)$

2030 FOF $I=:$ TO N

$2010101=1)$



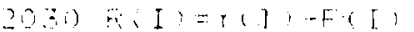

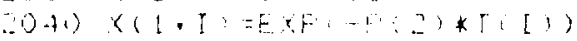

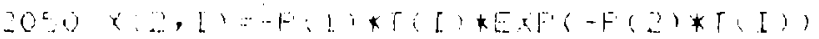





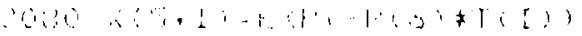

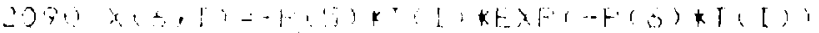

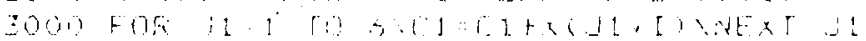

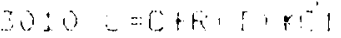

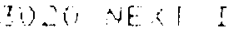

COMP17.BAS

Model 17 is unavailable for publication 
COMP18.BAS

30 FRINT "LGOSTO GROWTH CUFWE"

$320 \quad M=3$

2000 REM LOOTSTTE GROWTH CUFUE

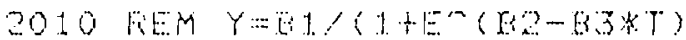

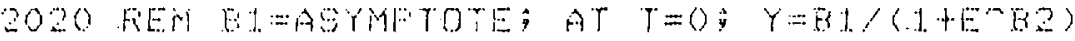

$2030 \quad 0=0$

2040 FOF I $=1$ TO N

200 a $1=E X F(F(2)-F(3) * T(I))$

$2060 F(I)=F(1) ;(1+A])$

$2070 R(I)=Y(T)-F(\Gamma)$

$2080 \times(1,1)=1 ;(1+1,1)$

$2090 \times(2,1) \div(-\cdots(1)$ KA 1$) /(1+A 1) \cdots 2$

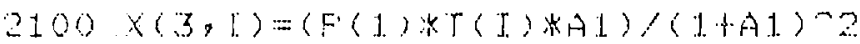

$2110 \quad C=C+F(I) *(X(1, I)+X(2, I)+X(z, \Gamma))$

2120 NEXT I.

\section{COMP19.BAS}

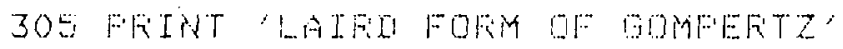

$320 \quad M=3$

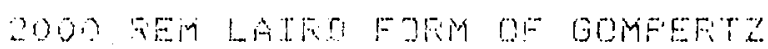

2010 FEM LAERE $31=E Q G$ WETGH

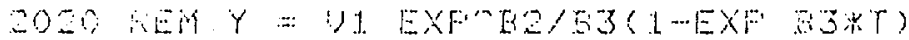

$2030 \quad C=0$

2035 FOFi I. $=1$. TO N

2040 A $1=F(\Omega) / F(3)$



2060 A $3=E \times F(A) *(1-\hat{A} 2))$

2070 A A F F (3) 次 T J)次A



2090 F(I) F( 1$)$ *A3

$2100 \times(1,1)=03$

- $110 \times(2, I)=((F(1) / F(3) / K A) *(1-A)$

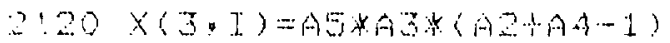

$2130 \quad \mathrm{C}(\mathrm{I})=\mathrm{Y}(I)-F(I)$

$2100=C+C(I) \times(X(1, I)+X(2, I)+X(Z, I)$

IDO AEXT I. 
COMP99.BAS




105 OFEN BS FOF TNFUT AS FILE H

2OU POF - I $\because$ L TO 1000

205 IF LND II THEN 200

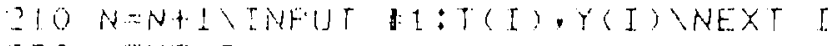

220 INE \& T

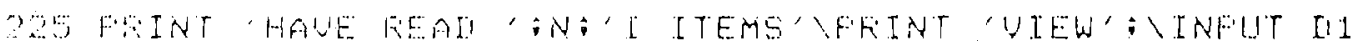

230 IF $\quad[1=0$. THE 230

240 PE:

271 . Fil:

27. FIE

2.35 sin

$\therefore 4$ Fim

$\therefore+1,1 . M$

SU. एEM



25S REM

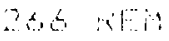

3060 ro 500

8010 L.0.5 : 


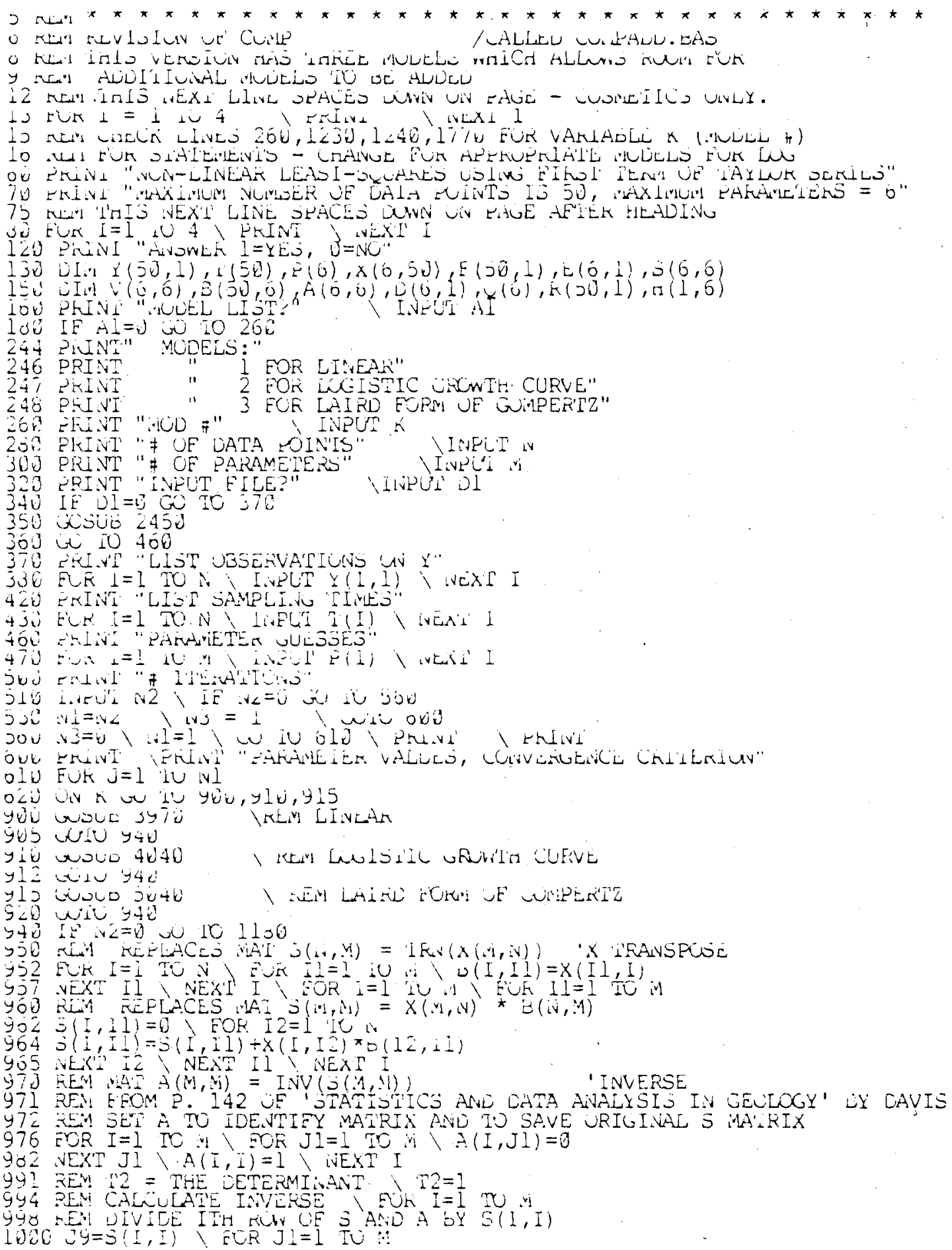




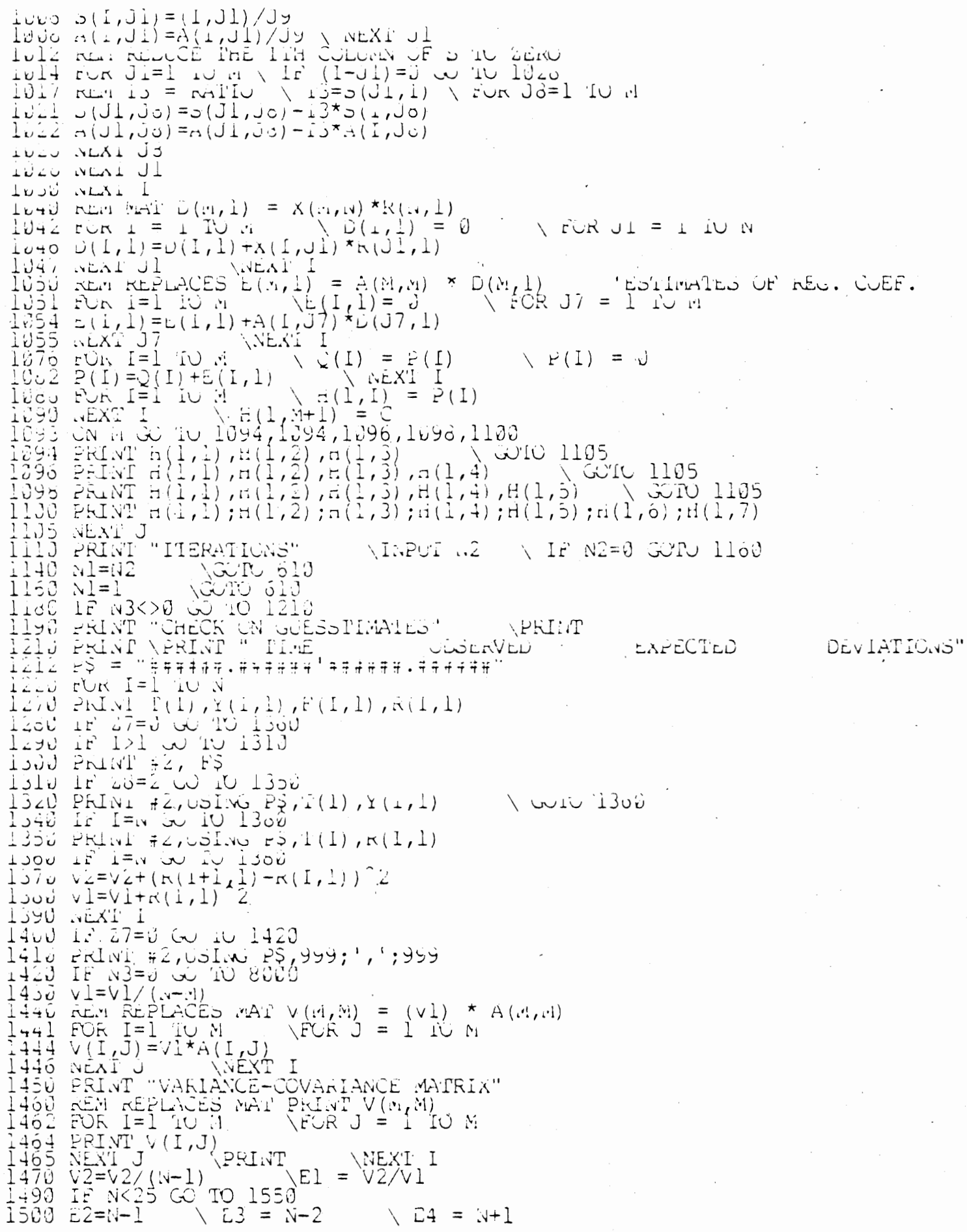




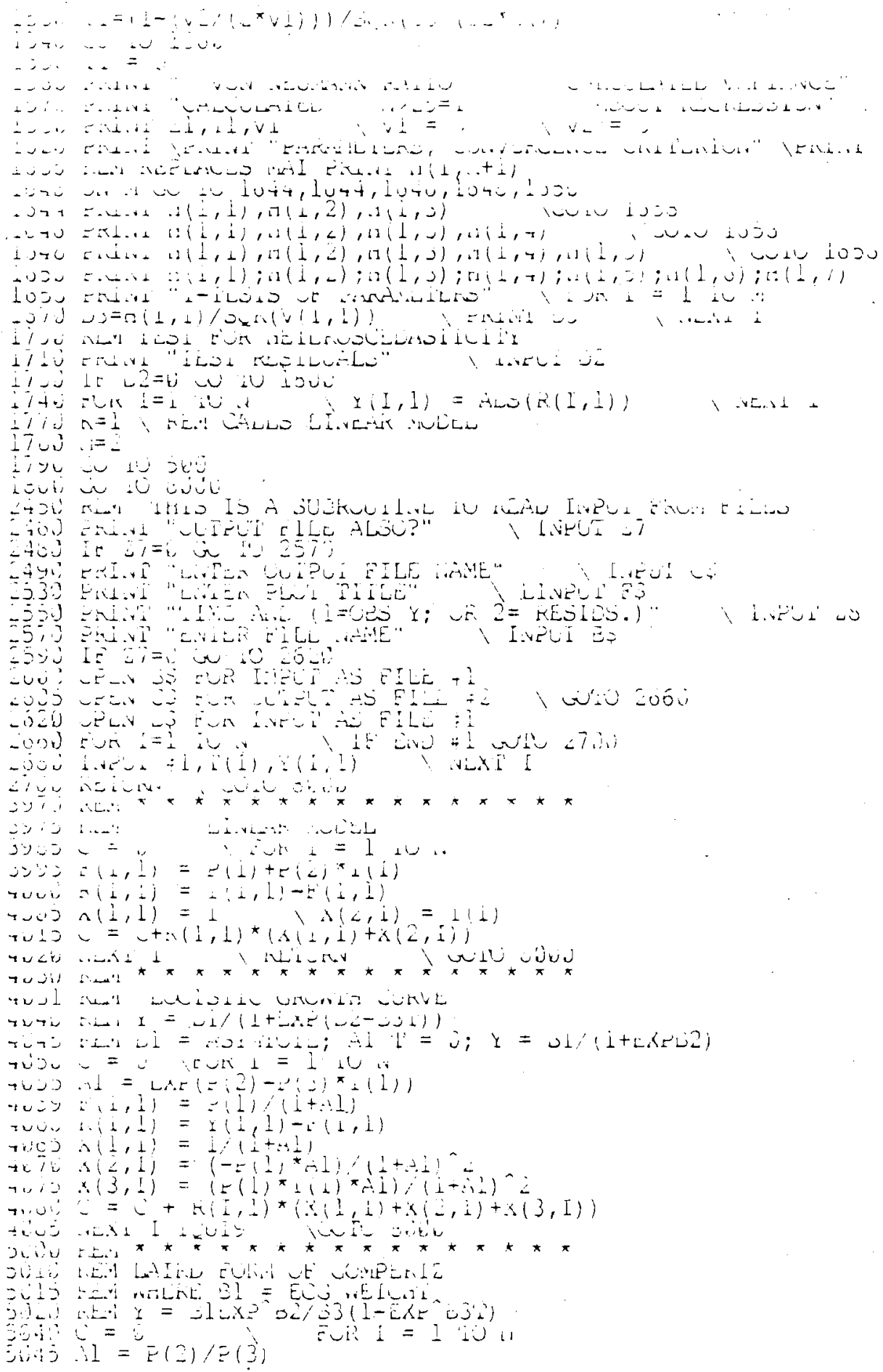


$50504=E x(-P(3) * T(I))$

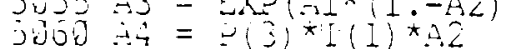

$500=0(1) * 3(2) /(3)(3)) " 2$

$56,5 \therefore(1, I)=A j$

$5000 x(2,1)=(1+(1),(3)) * A 3) *(1-.22)$

$200 j \delta(j, 1)=A j \times 3 \times(A L+A \dot{A}-1$.

ouyu $n(1,1)=1(1,1,-E(1,1)$

ojev $y=-n(1,1) *(x(1,1)+\alpha(2,1)+x(j, 1))$

UUty atsil I

outj killtw

uvioj L.W 


\section{DISTRIBUTION}

No. of

Copies

\section{OFFSITE}

1 A. S. Churm

DOE Chicago Patent Group

$9300 \mathrm{~S}$. Cass Ave.

Argonne, IL 60439

27 DOE Technical Information Center

Richard J. 01son

Oak Ridge National. Laboratory

Environnental Sciences Div.

Building 2001, Box $x$

Cak Ridge, TN 37830

W. Van Winkle

Oak Ridge National Laboratory

Environmental Sciences Div.

Building 2001 , Box $X$

Oak Ridge, TN 37330

Rodrey Strand

Oak. Ridge National Laboratory

Environmental Sciences Div.

Building 2001 , Box $X$

Oak Ridge, TN 37830

Vincent Schultz

Washington State University

Zoology Department

Puliman, WA 99163

A. J. Hulbert

Lovelace Biomedical and

Environmental Research

Laboratory

Inhalation Toxicology Research

Institute

P.0. Box 5890

Albuquerque, Nin 87115
No. of

Copies

J. L. Pinder, III

Savannah River Ecology Laboratory

Savannah River Plant

Drawer $E$

Aiken, SC 29801

Robert L. Watters

Department of Energy

Division of Biomedical and

Environmental Research

Washington, DC 20545

John H. Wilson, Jr.

Department of Energy

Division of Biomedical and

Environmental Research

Washington, DC 20545

Ishwar P. Murarka

Argonne National Laboratory

Division of Environmental

Impact Studies

9700 S. Cass Ave.

Argonne, IL 60439

Tom Hakonson

Los Alamos Scientific

Laboratory

H-8 Environmental Studies

P.0. Box 1663

Los Alamos, NM 87545

Gary white

Los Alamos Scientific

Laboratory

H-8 Environmental Studies

P.0. Box 1663

Los Alamos, NM 87545 
1 U.S. Department of Energy Richland Dperations office

90 Battelle-ilorthwest

R. L. Buscinbom

ii. I. Cochran

P. J. Dionne

P. G. Doctor

L. L. Eberhardt

R. O. Gilbert

J. L. Helbling

M. A. Hill

R. L. riooper

V. M. Lee

J. A. Mahaffey

D. H. Mckenzie

J. A. Merril

A. R. Olsen

R. H. Sauer

R. G. Schreckhise

J. iv. Thomas (20)

P. E. Tucker

B. E. Vaughan

C. R. Vatson (20)

Techrical Putlications (i)

Tecnrical information files

Ecosystams files

(3) 